\title{
Role of prosthodontist in forensic sciences - A review article
}

\author{
Rahul Sharma ${ }^{1}$, Dhruv Anand ${ }^{2, *}$, Ashish Choudhary ${ }^{3}$, Karunakar Shetty ${ }^{4}$ \\ ${ }^{1}$ Registrar, ${ }^{2}$ Lecturer, ${ }^{3}$ Professor, ${ }^{4}$ Associate Professor, ${ }^{2,3}$ Dept. of Prosthodontics, ${ }^{1}$ Saudi Commission of Health Specialities, \\ Prestige Dental Centre, Kingdom of Saudi Arabia, ${ }^{2,3}$ School of Dental Sciences, Sharda University, Greater Noida, Uttar Pradesh, \\ India, ${ }^{4}$ IBN Sina National College for Medical Sciences, Jeddah, Saudi Arabia \\ *Corresponding Author: \\ Email: diadhruv@gmail.com
}

\begin{abstract}
Forensic odontology has recently become an integral part of forensic science. Since, 100 years this science has been utilizing dental or oro-facial findings to aid in serving the judicial system. Dental identification holds an important role in the identification of remains after postmortem changes, traumatic tissue injury or lack of a fingerprint record. Forensic identification based on assessment of prosthodontic appliances and or prosthesis by methods such as of labeling of dentures and other prosthetic appliances could provide vital clues for victim identification. Other sources such as salivary sample collection from the prosthesis can provide a rich source of DNA collection. How, a prosthodontist can play a crucial role in forensic medicine by application of various modes that can aid in identification of a deceased individual is illustrated in this review article.
\end{abstract}

Keywords: Forensic Odontology, Denture labeling, DNA matching, Rugoscopy, Forensic medicine.

\section{Introduction}

Forensic dentistry engages the processing, reviewing, evaluation and presentation of dental evidence with the intention of contributing scientific and objective data as evidence in legal processes. Experienced professionals require a detective's qualities that require knowledge encompassing a number of disciplines, ${ }^{1}$ since the dental records obtained can identify an individual or provide the information needed by the authorities to establish neglect, fraud and/or abuse.

Dental structures are the hardest and the most resilient tissues of the human body. ${ }^{2}$ Teeth on exposure to postmortem influences survive longer than other body tissues as the materials used to restore damaged teeth are extremely resistant to physical, chemical and biological destruction. ${ }^{3}$

Identification with the help of dentistry, can have three different applications ${ }^{4}$ :

a. Comparative identification that helps in comparing the postmortem dental records with the antemortem records of an individual.

b. To ascertain the search of an individual when the antemortem records are not available and there are no possible data referred to the identity of the subject.

c. Identification of victims following mass disasters or catastrophes.

Forensic identification based on the assessment of prosthodontic methodology is gaining significance, as labeling of dentures and other prosthetic appliances could provide vital clues for patient identification ${ }^{5}$.

\section{History}

History dates back to 1775 , during the US Revolutionary War when Paul Revere, a young dentist, identified war casualties by assessment of their crown and bridgework. ${ }^{2}$ Later in 1885 , the burnt body of Countess of Salisbury was identified with the help of a gold denture.

After the Second World War, out of 819 soldiers only 9 could be identified with the help of dentures as labeling of the dentures and preservation of antemortem records were not much in practice at that time. ${ }^{6}$

In 1849, Dr. Parkman a professor at the Harvard University body was burned out completely. He was later, identified by charred fragment of a tooth fused to gold by Dr. N C Keep, who had previously made a removable denture for the victim.

In 1968, a badly mutilated body found on the railway line near Sydney was identified by a maxillary acrylic denture bearing a name inscribed on it. Identification of European tourists during tsunami was done by gold inlays, onlays, crowns, bridges and dental implants. ${ }^{7}$

In 1977, Hitler and his wife's bodies were identified using dental records with the help of radiographs and prostheses. ${ }^{8}$ Many more such as M. Raja Jayachandra Rathore of Canouj who died on the battle field in 1191 was also identified by his artificial anterior teeth. This was probably the first case of identification using dentition in India. ${ }^{9}$

On September 11, 2001, thousands of people lost their lives in the world trade center disaster in New York, U.S.A. Deoxyribo Nucleic Acid (DNA) extracts from tooth brushes of the victims were used in identification of some of the victims. ${ }^{9}$ 


\section{Discussion}

Legal identification of an individual's identity is 1 . based on numerous parameters centered around the appearance and personal features like identity cards, accessories, clothes etc.). However, it is not necessary that this may always be available or applicable necessitating the use of other sources of identification.

In general, certain characteristics such as age, gender, race, ethnicity and/or blood samples are used.2. Dental examinations are second only to fingerprints and play a fundamental role in medico-legal investigations including mass disasters. ${ }^{10}$

A prosthodontist can play a pivotal role in forensic identification by employing various methods and techniques available in literature. Various processes and systems are employed for identification and a prosthodontist can become a part of this team and render these services in a better way.

The Prosthodontist can contribute to forensic science in the following ways:

\section{Comparative Dental Identification}

This procedure of dental identification of a victim involves the matching or comparison of postmortem dental remains with antemortem dental records. ${ }^{8}$ However, antemortem data needs to be available for this methodology to be successful by keeping a record of the dental notes, radiographs, study models and clinical photographs by the dental professionals. ${ }^{11}$

\section{Prosthesis labeling}

Denture labeling has been well documented as a useful technique in the identification of the victims of fatal disasters as well as for the patients who suffer from mental disorders or psychiatric problems such as traumatic or senile loss of memory like dementia and Alzheimer's. ${ }^{12-15}$

The Australian Dental Association recommends labelling on all the dentures for residents as a health care norm ${ }^{35}$. Denture marking is also regulated by law in Sweden, Iceland and a few cities of the united states of America $^{36}$. Although no legal orders have been approved pertaining to this matter, it is still an ethical and social obligation on the part of the dental surgeon to do so.

In incinerated bodies of the victims, it is noted that the mandibular lingual posterior and the maxillary palatal posterior portions of the dentures are generally spared. Hence, these sites become the choice of areas for the labelling. . $^{16,17}$

Alloys such as cobalt chromium resist melting even in some cases of incinerated victims. Hence, the complete denture marking should not only be restricted to acrylic complete or partial dentures only but also be executed on to the ones made from these alloys.

Various other appliances in dentistry such as the ones used in orthodontics, maxillofacial prosthesis etc. should also be marked for identification. ${ }^{18}$
Denture labeling can be performed by two techniques:

Surface modification technique: It involves writing, scribing on the polished or tissue surface of the denture post fabrication with a water proof marker or embossing initials of the patient on the master cast. However, these methods are not permanent and may lead to food and debris accumulation making the surface prone to oral infections.

Inclusion technique: This technique involves the placement of metallic, nonmetallic labels or microchips during the denture processing stage. Patient's name or identification number is incorporated in the denture permanently. This technique might be time consuming and requires skill.

Paper strips: Incorporation of paper strips is an economical technique wherein a scribed paper strip is inserted between the slopes of the alveolar ridge and the center of the palate. The paper strip is covered with the acrylic resin before the final closure for acrylisation of the denture is done. ${ }^{19}$

ID Band: Stainless steel bands or fire resistant materials like titanium foil, matrix bands containing the information of the denture wearer can be used to mark the dentures. ${ }^{19}$

Laser etch: Laser etching is a technique wherein copper vapour laser can be used to etch the metal surface of the prosthesis. This method is expensive and needs special training. ${ }^{19}$

Denture micro labeling system: Micro labeling procedure contains transparency film with name and other information of the patient incorporated onto the dentures. Chemical treatment with $100 \%$ cyanoacrylic acid is done prior to the incorporation of the label into the denture. A thin layer of autopolymerising clear acrylic resin can then be coated. ${ }^{19,20}$

T- Bar: A T shaped clear PMMA resin bar is constructed by trimming the base plate wax and is then acrylized with clear or pink PMMA. A printed identification is fixed against the flat surface of the bar. It is then highly polished to produce a clear window displaying the necessary information of the denture wearer. ${ }^{21}$

Lenticular card: Lenticular printing is a multistep process which includes creating a lenticular image from minimum two existing images, and combining it with a lenticular lens. Images are produced with an illusion of depth, morphology or the ability to move or change as the image is viewed from different angles. Each image is sliced into strips, which are then interlaced the other images. These are then printed on the back side of a synthetic paper and laminated on the lens. One of the disadvantages of this method is that it may not withstand fire and the information once written cannot be altered again. ${ }^{22}$

RFID Tags: Radio Frequency Identification (RFID) is a cosmetic labeling method of identification with the help of using radio waves. It consists of a data carrier also referred to as tag and a reader with an antenna. The tag consists of a microchip that stores patient's information. 
The reader reads the information contained in the tag. The tag is programmed by connecting to the computer and then the programmed tag is incorporated into the channel on the posterior buccal surface of the denture. Clear acrylic resin is then placed over the tag to recontour the denture. ${ }^{23}$ This is an expensive technique and the tag is not fire proof.

\section{DNA Identification}

DNA patters for each individual are unique. The resistant nature of dental tissues to external trauma like incineration, immersion, mutilation and decomposition, teeth represent a rich source of DNA material. ${ }^{24}$ This DNA biological material can provide the necessary link to prove identity of a victim when traditional dental identification methods fail. This identification method should always be used as a supplementary method. ${ }^{25}$

\section{Rugoscopy}

Rugoscopy is the study of palatal rugae. The Rugae are irregular, assymetrical ridges of mucous membrane extending laterally from the incisive papillae located in the anterior part of the mid palatine raphe. The arrangement of these rugae are considered unique to an individual and can be used as a trusted method in postmortem cases. The rugae is anatomically surrounded by cheeks, lips, tongue, buccal pad of fat, teeth and alveolar bone that keeps them well protected from trauma and high temperatures. They can be used as a reliably reference landmark during forensic identification subjected to prior storage of antemortem data. A prosthodontist may be able to identify denture wearer by the identification of the rugae pattern. ${ }^{26}$

\section{Photographic Superimposition}

This technique of superimposition and $\mathrm{x}$-ray tomography can be very effective in identifying between a complete denture and a skull. Since the morphological characteristics of the denture base, including the arrangement of the artificial teeth have to be compared with those of the surfaces of the jaw bones, it become difficult since the morphological characteristics of the denture base, including the arrangement of the artificial teeth, have to be compared with those of the surfaces of the jaw bones. ${ }^{27}$

\section{Dental Implants Identification}

Dental implants can play an important role in identification of date. DNA identification, fingerprint and dental comparison are primary scientific identifiers. However, in some situations where a victim has been incinerated, there may be loss of finger print detail and denaturing of DNA. The physical properties of titanium like high corrosion resistance, high structural strength and high melting point, suggest the retention of implants following most physical assaults. ${ }^{28}$ Berketa et al placed Implants in sheep mandibles and then cremated entire sheep heads in a commercial cremator. $^{29}$ The information regarding batch number was laser etched within the chamber of the Straumann ${ }^{\mathrm{TM}}$ implants. Following retrieval of the implants, the batch number within the implant was still visible, which could significantly add importance to the identification of a victim. The result indicated that there was an intact identifiable batch number on removal of the abutment. Hence, it was suggested if the companies constructing implants place individual serial numbers rather than batch numbers on these implants then this can become a potential new approach for the identification of the deceased. ${ }^{30}$

\section{Conclusion}

Application of forensic dentistry for the identification of a victim is not anymore a recent concept. The oral cavity is a rich and noninvasive source of DNA and can be used for the identifications for providing information needed in legal processes. However, there is a need to motivate dental practitioners to maintain dental records and apply distinctive markers in prosthesis and also maintain a database which can be made available on request. More studies should also be performed to better understand the population based characteristics in high risk areas to explore this interesting field of Forensic Sciences.

Funding: No funding sources.

Conflict of interest: None declared.

\section{References}

1. Sukul B, Deb U, Ghosh S. Why a "dental surgeon" for identification in forensic science? J Indian Med Assoc 2010;108:769-70,775.

2. Sweet D, DiZinno JA. Personal identification through dental evidence tooth fragments to DNA. J Calif Dent Assoc 1996;24:35-42.

3. Gosavi S, Gosavi S. Forensic odontology: A Prosthodontic view. J Forensic Dent Sci 2012;4:38-41.

4. Sweet D, DiZinno JA. Personal identification through dental evidence--tooth fragments to DNA. J Calif Dent Assoc 1996;24:35-42.

5. Takahashi F, Koji T, Morita O. A new method for denture identification. Dent Mater J 2008;27:278-83.

6. MacEntee MI, Campbell T. Personal identification using dental prostheses. J Prosthet Dent 1979;41:377-80.

7. Lau G, Tan WF, Tan PH. After the Indian ocean tsunami: Singapore's contribution to the international disaster victim identification effect in Thailand. Ann Acad Med Singapore 2005;34:341-51.

8. Bagi BS. Role of forensic odontology in medicine. $J$ Indian Dent Assoc 1977;49:359-63.

9. Sansare K. Forensic odontology, historical perspective. Indian J Dent Res 1995;6:55-7.

10. Stimson PG, Mertz CA . Forensic Dentistry. CRC Press, New York;1997:1-45

11. Al-Ahmad SH. Forensic Odontology. Smile Dent $J$ 2009;4:22-4

12. Shimoyama K, Ogawa N, Umino M, Nagao M, Odagiri $\mathrm{K}$. The need for a denture marking system in geriatric institutions. J JGerodont 1992;7:8-13.

13. Cunningham M, Hoad-Reddick G. Attitudes to identification of dentures: The patients perspective. Quintessence Int 1993;24:267-70. 
14. Borrman H, Thomas CJ, Engstrom EU. Denture marking. Clinical and technical aspects. J Forensic Odontostomatol 1995;13:14-7.

15. Kanai H, Kasahara H, Ohta S, Koshiba K, Hosaka K, Watanabe T, et al. Denture identification for the disabled elderly. Effect of name marking on removable denture. $J$ JGerodont 1996;11:18-24

16. Ling BC, Nambiar P. Denture marking for the Malaysian population Ann Dent Univ Malaya 1996;3:43-5.

17. McGivney J. Marking of removable dentures. In: Averill DC, editor. Manual of Forensic Odontology. 2nd ed. USA: Am Soc Forensic Sci 1991. p. 62-6.

18. Harvey W. Identity by teeth and the marking of dentures. Br Dent J 1966;121:334-40.

19. Data. P, Sood. S. The various methods and benefits of denture labeling. J Forensic Dent Sci 2010;2(2):53-8

20. Ibrahim WM. Denture microlabeling technique. $J$ Prosthet Dent 1996;76:104.

21. Ryan LD, Keller JB, Rogers DE, Schaeffer L. Clear acrylic resin T-bar used in denture identification. $J$ Prosthet Dent 1993;70:189-90

22. Colvenkar SS. Lenticular card: A new method for denture identification. Indian J Dent Res 2010; 21:112-4.

23. Millet $\mathrm{C}$, Jeannin C. Incorporation of microchips to facilitate denture identification by radio frequency tagging. J Prosthet Dent 2004;92:588-90

24. Schwartz TR, Schwartz EA, Mieszerski L, McNally L, Kobilinsky L. Characterization of deoxyribonucleic acid (DNA) obtained from teeth subjected to various environmental conditions. J Forensic Sci 1991;36:979-90
25. Hirsch C, Brondolo T, Butcher B. Report to HE Dr. Surachai,Minister of Public Health, Thailand, and Dr. William Aldis, WHO representative to Thailand World Health Organization. Assessment of victim identification operations: Thailand tsunami disaster. New York: City of New York office of Chief Medical Examiner; 2005. p. 11.

26. Goswami R, Garg R, Jolly R. Role of prosthodontics in forensic odontology. Int J Clin Dent Sci 2011;2:85-9.

27. Minaguchi K, Hanaoka Y, Kiriyama T, Yamamoto K, Kuroyanagi K. Personal identification of a skull by a complete denture-application of superimposition and $\mathrm{X}$-ray computed tomography analysis Nihon HoigakuZasshi1994;48:282-8.

28. Berketa J, James H, Marino V. Dental implant changes following incineration. Forensic Sci Int 2011;207:50-4.

29. Berketa J, James H, Marino V. Survival of batch numbers within dental implants following incineration as an aid to identification. J Forensic Odontostomatol 2010;28:1-4.

30. Berketa J, James H, Marino V. A pilot study in the recovery and recognition of non-osseointegrated dental implants following cremation. J Forensic Odontostomatol 2011;29:38-44.

How to cite the article: Sharma R., Anand D., Choudhary A., Shetty K. Role of prosthodontist in forensic sciences - A review article. Ann Prosthodont Restor Dent 2018;4(3):68-71. 